\title{
Minimum Quality Standards and Collusion
}

\author{
Giulio Ecchia* ${ }^{\dagger}$ \\ and \\ Luca Lambertini* ${ }^{\dagger}$ \\ *Department of Economics \\ University of Bologna \\ and \\ ${ }^{\dagger}$ Linacre College \\ University of Oxford
}

October 30, 1995

\begin{abstract}
We model the introduction of a minimum quality standard in a vertically differentiated duopoly. We extend the literature in determining the standard endogenously, showing that the maximisation of social welfare entails an increase in the surplus accruing to consumers served by the low quality firm and a decrease in the surplus of the remaining consumers. Then, we consider the effects of the standard on the stability of price collusion, proving that the standard makes it more difficult for firms to collude if consumers are sufficiently rich.
\end{abstract}

J.e.l. classification numbers: L13, L50

Keywords: minimum quality standard, collusion, cartel stability.

Corresponding Author:

Luca Lambertini

Department of Economics- University of Bologna

Strada Maggiore, 45- 40125 Bologna- Italy

Fax.:+39-51-6402664

E-mail: LAMBERTI@BOPH01.CINECA.IT 


\section{Introduction}

The regulation of an imperfectly competitive market with vertically differentiated products has been long debated in the literature since the seminal contributions of Spence (1975) and Sheshinski (1976). More recently, various papers have examined the consequences of the adoption of a minimum quality standard in oligopolistic markets where each firm supplies at least one variety (see, among others, Besanko et al.,1987 and 1988; Ronnen, 1991 and Crampes and Hollander, 1995). Both Ronnen (1991) and Crampes and Hollander (1995) consider a duopolistic market with single-product firms. The introduction of the minimum quality standard is then analysed as an exogenous constraint on the low quality firm to increase its quality level. The introduction of the standard gives a strategic advantage and higher profits to the low quality firm and reduces the degree of differentiation in the market. Although the standard exerts a positive welfare effect, its consequences, as far as consumers' surplus is concerned, are quite different depending on the cost functions of firms. Ronnen adopts a model where the provision of quality entails only a fixed cost for firms: in this case, all consumers benefit from the standard because the price-cost margin is reduced. Crampes and Hollander show that the same result holds in a model where variable costs depend on both quality and quantity, provided that the standard reduces the degree of differentiation sufficiently. Otherwise, only the consumers served by the low quality firm benefit from the standard, although social welfare always increases ${ }^{1}$. In both papers, the adoption of the standard entails a reduction of product differentiation in the market and an asymmetric change in firms' profits. This raises the question of whether firms could find it easier to collude in presence of a standard.

There are several contributions dealing with price collusion in endogenously differentiated product settings (see, for instance, Chang, 1991; Ross, 1992 and Friedman and Thisse, 1993). They mainly consider horizontal differentiation models showing that the stability of collusion increases as the degree of product differentiation increases. In this case, the symmetry of the models implies that as the degree of substitutability decreases, the gain associated with deviation from the cartel agreement decreases as well. To our knowledge, the only paper investigating the issue of cartel stability in a vertically differentiation setting is that of Haeckner (1994). He analyses the stability of

\footnotetext{
${ }^{1}$ For an analysis of the strategic role of quality standards in an international oligopolistic setting, see Motta and Thisse, 1993, and Boom, 1995.
} 
collusion in a model of endogenous vertical differentiation using a framework à la Shaked and Sutton (1982). He shows that price collusion is more easily sustained the closer the products are in the quality range. This is due to the fact that, with vertical differentiation, the punishment phase introduces an asymmetry in cartel behaviour which is absent in the horizontal differentiation models à la Hotelling (see Chang, 1991).

In this paper, we extend the previous literature in two directions. First, we endogenise explicitly the choice of the minimum quality standard which maximises social welfare. Second, we consider the possibility that the reduction of product differentiation due to the standard may trigger collusive behaviours between firms in order to safeguard profits. We model a duopoly market à la Mussa-Rosen (1978) where firms produce only one variety and production involves variable costs convex in quality and an exogenous fixed cost. We show that the endogenous choice of the standard increases social welfare so that the gains for the low quality firm and low income consumers outweigh the losses suffered by the high quality firm and high income consumers. Moreover, we prove that the adoption of the standard makes it more difficult for firms to collude in prices, if consumers are sufficiently rich. This shows that the minimum quality standard, in addition to welfare gains, provides also pro-competitive benefits in the long-run.

The paper is organised as follows. Section two presents the basic model and describes the duopoly and monopoly equibria without the minimum quality standard. The endogenous choice of the minimum quality and its effects are presented in section three. Section four deals with price collusion. Section five contains some final remarks.

\section{The model}

\subsection{Assumptions and notation}

We consider a market for vertically differentiated products. There is a continuum of consumers whose types are identified by $\theta$, uniformly distributed in the interval [a,b], with $a=b-1$ and $b \geq 5 / 4^{2}$. The parameter $\theta$ represents consumers' marginal willingness to pay for quality. Each consumer is assumed to buy one unit of the vertically differentiated good in order to maximise the following indirect utility function:

$$
U=\theta q-p
$$

\footnotetext{
${ }^{2}$ This condition ensures the existence of the duopoly equilibrium (see Cremer and Thisse (1994) on this point).
} 
where $q$ indicates the quality of the product and $\mathrm{p}$ is the market price at which that variety is supplied. In other terms, we assume full market coverage. This assumption can be justified by envisaging a paternalistic public agency which imposes firms to guarantee universal service.

The production technology involves variable costs which are convex in quality and linear in quantity and a sunk cost $\mathrm{k}$, related to the development of the product. The corresponding cost function is defined as:

$$
C=t q^{2} x+k, t>0
$$

where $\mathrm{x}$ denotes the output level. We also assume that $\mathrm{k}$ is sufficiently small to allow for strictly positive profits for firms active in the market.

We suppose that only two qualities (which we indicate as high and low) are supplied in the market, with $\mathrm{q}_{\mathrm{H}}>\mathrm{q}_{\mathrm{L}}$. Hence $\theta_{\mathrm{i}}$, the index of the consumer indifferent between the two varieties, is defined as

$$
\theta_{i}=\left(p_{H}-p_{L}\right) /\left(q_{H}-q_{L}\right)
$$

So that market demand for the two varieties are

$$
\begin{aligned}
& x_{H}=b-\theta_{i} \\
& x_{L}=\theta_{i}-a
\end{aligned}
$$

\subsection{Duopoly equilibrium}

We first take into account a duopoly market where each firm supplies a single quality. Competition takes place in two stages. In the first, firms choose qualities and in the second they compete in prices. The solution concept applied is the subgame perfect equilibrium by backward induction.

The profit function of firm $i$ is defined as $^{3}$

$$
\pi_{i}=\left(p_{i}-t q_{i}^{2}\right) x_{i} ; i=H, L
$$

\footnotetext{
${ }^{3}$ For simplicity of notation, henceforth we shall consider firms' profits gross of fixed costs k.
} 
In the second stage, firms choose prices to maximise profits, given the quality levels set in the first stage. The corresponding first order conditions for a maximum are ${ }^{4}$

$$
\begin{gathered}
\delta \pi_{H} / \delta p_{H}=\left(p_{L}-2 p_{H}+b q_{H}-b q_{L}+t q_{H}^{2}\right) /\left(q_{H}-q_{L}\right)=0 \\
\delta \pi_{L} / \delta p_{L}=\left(p_{H}-2 p_{L}+q_{H}-b q_{H}-q_{L}+b q_{L}+t q_{L}^{2}\right) /\left(q_{H}-q_{L}\right)=0
\end{gathered}
$$

Then, the resulting equilibrium prices are

$$
\begin{gathered}
p_{H}^{N}=\left(q_{H}+b q_{H}-q_{L}-b q_{L}+2 t q_{H}^{2}+t q_{L}^{2}\right) / 3 \\
p_{L}^{N}=\left(2 q_{H}-b q_{H}-2 q_{L}-b q_{L}+t q_{H}^{2}+2 t q_{L}^{2}\right) / 3
\end{gathered}
$$

where the superscript $\mathrm{N}$ stands for Nash equilibrium.

Substituting the equilibrium prices in the profit functions of the firms we can obtain the following equilibrium quality levels for the two firms

$$
\begin{gathered}
q_{H}{ }^{N}=(4 b+1) / 8 t \\
q_{L}^{N}=(4 b-5) / 8 t
\end{gathered}
$$

Since the duopoly is symmetric, demands are both equal to $1 / 2$. The corresponding profits amount to $\pi_{\mathrm{i}}^{\mathrm{N}}=3 / 16 \mathrm{t} ; \mathrm{i}=\mathrm{H}, \mathrm{L}$ (see Cremer and Thisse (1994)).

For future reference, it is also convenient to calculate the social welfare corresponding to the duopoly equilibrium. Assuming a benevolent social planner, her utilitarian social welfare function, defined as the sum of consumer and producer surplus, can be written as

$$
W=\int_{a}^{i}\left(\theta q_{L}-t q_{L}^{2}\right) d \theta+\int_{i}^{b}\left(\theta q_{H}-t q_{H}^{2}\right) d \theta
$$

\footnotetext{
${ }^{4}$ In this case, as in the rest of the paper, we do not present the second order conditions for optima, which, however, can be shown to hold throughout.
} 
The welfare level corresponding to the duopoly equilibrium is $\mathrm{W}_{\mathrm{N}}=\left(16 \mathrm{~b}^{2}-16 \mathrm{~b}-1\right) / 64 \mathrm{t}$. In addition, we can also calculate the consumer surplus for the two segments of the market, which are, respectively, $\mathrm{CS}_{\mathrm{L}}{ }^{\mathrm{N}}=\left(16 \mathrm{~b}^{2}-24 \mathrm{~b}-19\right) /(128 \mathrm{t})$ and $\mathrm{CS}_{\mathrm{H}}{ }^{\mathrm{N}}=\left(16 \mathrm{~b}^{2}-8 \mathrm{~b}-\right.$ $27) /(128 t)$.

\subsection{Monopoly}

Consider now the case of a private monopolist producing two varieties. The profits of the monopolist are defined as:

$$
\pi^{M}=\left(p_{H}-t q_{H}^{2}\right) x_{H}+\left(p_{L}-t q_{L}^{2}\right) x_{L}
$$

The monopolist chooses prices to maximise profits, under the assumption that all the consumers must be served. Thus, monopoly prices (see Mussa and Rosen (1978); Itoh, (1983)) are:

$$
\begin{gathered}
p_{L}{ }^{M}=(b-1) q_{L} \\
p_{H}{ }^{M}=\left(b q_{H}-2 q_{L}+b q_{L}+t q_{H}^{2}-t q_{L}{ }^{2}\right) / 2
\end{gathered}
$$

The qualities result $\mathrm{q}_{\mathrm{L}}{ }^{\mathrm{M}}=(2 \mathrm{~b}-3) / 4 \mathrm{t}$ and $\mathrm{q}_{\mathrm{H}}{ }^{\mathrm{M}}=(2 \mathrm{~b}-1) / 4 \mathrm{t}$; the monopolist's profits are equal to $\pi^{\mathrm{M}}=\left(4 \mathrm{~b}^{2}-8 \mathrm{~b}+5\right) / 16 \mathrm{t}$. The corresponding level of social welfare is $\mathrm{W}^{\mathrm{M}}=\left(4 \mathrm{~b}^{2}-4 \mathrm{~b}-\right.$ $3) / 16 \mathrm{t}$.

It can be quickly verified that the profit maximising monopolist distorts quality levels as compared to a social optimum ${ }^{5}$. In fact, the social planner would choose the quality levels in order to maximise (9). The resulting qualities would be $\mathrm{q}_{\mathrm{L}}^{\mathrm{SP}}=(4 \mathrm{~b}-3)$ $/ 8 \mathrm{t}$ and $\mathrm{q}_{\mathrm{H}} \mathrm{SP}^{\mathrm{s}}=(4 \mathrm{~b}-1) / 8 \mathrm{t}$ and the corresponding level of social welfare would be equal to $\mathrm{W}^{\mathrm{SP}}=\left(16 \mathrm{~b}^{2}-16 \mathrm{~b}+5\right) / 64 \mathrm{t}$.

\section{The introduction of a minimum quality standard}

Suppose that a public authority intervenes to regulate the behaviour of firms as far as their quality choice is concerned, by introducing a minimum quality standard ${ }^{6}$. The social

\footnotetext{
${ }^{5}$ For a seminal discussion of this point, see Spence (1975).

${ }^{6}$ In order to induce the low quality firm to adhere to the standard, we can assume that the authority introduces a penalty which makes convenient to the firm to set a quality level equal to the standard.
} 
planner sets the standard in order to maximise social welfare, taking duopolistic price competition as given. Thus, the minimum quality standard chosen by the social planner will satisfy the first order condition

$$
\delta W / \delta q_{L}=\left(14 b-8-5 b^{2}-28 t q_{L}-20 t q_{L}+5 t^{2} q_{H}^{2}-10 t^{2} q_{H} q_{L}-15 t^{2} q_{L}^{2}\right) / 18=0
$$

while the high quality firms will simultaneously set its quality level in order to maximise profits, so that

$$
\delta \pi_{H} / \delta q_{H}=\left(1+b-t q_{H}-t q_{L}\right)\left(1+b-3 t q_{H}+t q_{L}\right) / 9=0
$$

The solution of the social planner's maximisation problem is given by

$$
q_{L}^{S}=(20 b-34+9 \sqrt{6}) / 40 t
$$

which corresponds to the minimum quality standard ${ }^{7}$, whereas the quality set by the high quality firm is

$$
q_{H}^{S}=(20 b+2+3 \sqrt{ } 6) / 40 t
$$

It is easy to see that the introduction of the minimum quality standard increases the levels of quality produced in the market, that is $\mathrm{q}_{\mathrm{L}} \mathrm{S}$ is greater than $\mathrm{q}_{\mathrm{L}}$ and $\mathrm{q}_{\mathrm{H}} \mathrm{S}$ is greater than $\mathrm{q}_{\mathrm{H}}$. Since the minimum quality standard is higher than the lower quality previously offered in the market in absence of regulation, the high quality firm increases its quality level since qualities are strategic complements (see Crampes and Hollander 1995, Bulow et al.1985). The effect of the standard on the degree of differentiation in the market is summarised in the following fact.

Fact 1: the setting of the minimum quality standard decreases the degree of differentiation in the market.

\footnotetext{
${ }^{7}$ Crampes and Hollander (1995, p.76) state that setting a quality standard is equivalent to granting the low quality firm the ability to commit in quality. In fact, it can be shown that the standard is slighly lower than the quality chosen by a firms acting as a Stackelberg leader in the quality stage of the game.
} 
Using (8a,b) and (14-15), it is immediate to verify that $\left(q_{H}^{S}-q_{L}^{S}\right)$ is smaller than $\left(q_{H}{ }^{N}\right.$ $\left.q_{L}^{N}\right)$.

The quantities produced by the low and the high quality firms are, respectively,

$$
\begin{gathered}
x_{H}{ }^{S}=(6 \sqrt{ } 6-21) /(5 \sqrt{ } 6-30) \cong 0.355051 \\
x_{L}{ }^{S}=(9+\sqrt{ } 6) /(30-5 \sqrt{ } 6) \cong 0.644949
\end{gathered}
$$

The effect of the introduction of the minimum quality standard on the market shares of the two firms is summarised in the following fact.

Fact 2: the presence of the minimum quality standard reduces the demand for the high quality good while increasing demand for the low quality good.

The corresponding profits for the firms are ${ }^{8}$

$$
\begin{gathered}
\pi_{L}^{S}=(54 \sqrt{ } 6+261) / 500 t \sqrt{ } 6(1-\sqrt{ } 6) \cong 0.22153 / t \\
\pi_{H}^{S}=(756 \sqrt{ } 6-1971) / 500 t \sqrt{ } 6(1-\sqrt{ } 6) \cong 0.06714 / t
\end{gathered}
$$

Fact 3: the introduction of the quality standard increases the profits of the low quality firm and decreases the profits of the high quality firm due to the reduction of the degree of differentiation between products in equilibrium.

It is also worth noting that total industry profits after the introduction of the minimum quality standard are smaller than total profits in the duopoly equilibrium without standard ${ }^{9}$.

\footnotetext{
${ }^{8}$ It is easy to verify that the optimal quality choice for the low quality firm under the constraint represented by the standard coincides indeed with the latter, since both the first and the second derivatives of its profit function with respect to $\mathrm{q}_{\mathrm{L}}$ are negative in correspondence of the minimum quality standard.
} 
The level of social welfare is

$W^{S}=\frac{\left(42000 b^{2}+12000 \sqrt{6}+12000 b \sqrt{6}-42000 b+4560 \sqrt{ } 6-9210\right)}{(48000 t(7 / 2+\sqrt{ } 6))}$

Fact 4: the introduction of the quality standard increases social welfare compared to the duopoly equilibrium.

It is immediate to show that $\mathrm{W}^{\mathrm{S}}$ is greater than $\mathrm{W}^{\mathrm{N}}$. The increase in social welfare is due to: a) an increase in the level of qualiy of both goods produced; b) an increase in price competition between the two firms, since the difference $\left(\mathrm{q}_{\mathrm{H}}{ }^{\mathrm{S}}-\mathrm{q}_{\mathrm{L}}{ }^{\mathrm{S}}\right)$ is smaller than the corresponding difference $\left(\mathrm{q}_{\mathrm{H}}{ }^{\mathrm{N}}-\mathrm{q}_{\mathrm{L}}{ }^{\mathrm{N}}\right)$ in the duopoly equilibrium. Moreover, the increase in social welfare is due to the fact that the introduction of the standard entails an increase in consumer surplus that outweighs the decrease in total industry profits. However, the effect of the standard on consumers' surplus is different across consumers, as stated in the following fact.

Fact 5: the introduction of the quality standard always increases the surplus accruing to consumers who purchase the low quality good while it decreases the surplus for the consumers served by the high quality firm for b sufficiently high.

This is immediate from a straightforward comparison between the equilibrium levels of the consumers' surplus in the two settings (see appendix B).

\section{Price collusion}

In this section we consider collusive behaviour in the market stage of the game, with and without minimum quality standard. In such a setting, qualities are still set noncooperatively by firms. This assumption can be justified on the grounds of the fact that quality choices can be interpreted as long-run commitments for firms and thus it would be too difficult for them to reach an agreement in both stages of the game. The price setting behaviour of the cartel is analogous to that of a profit-seeking monopolist as shown in section 2.3 .

\footnotetext{
${ }^{9}$ From equation (24b), it emerges that the sunk cost $\mathrm{k}$ must be not greater than $0.06714 / \mathrm{t}$. In fact, if $\mathrm{k}=0.06714 / \mathrm{t}$, only two firms can operate in the market when a minimum quality standard is present.
} 
In order to measure the stability of collusion, we can resort, as usual, to the definition of critical discount factor, that is

$$
\alpha_{i}^{*}=\left(\pi_{i}^{D}-\pi_{i}^{C}\right) /\left(\pi_{i}^{D}-\pi_{i}^{N}\right) ; i=H, L
$$

where $\pi_{\mathrm{i}}^{\mathrm{N}}$ indicates firm i's non-cooperative profits; $\pi_{\mathrm{i}}^{\mathrm{C}}$ indicates firm i's collusive profits and finally $\pi_{\mathrm{i}}^{\mathrm{D}}$ denotes firm i's profits from deviation from the price cartel. The stability of the cartel requires that both firms' discount factors are greater than the critical value defined in (19). Cartel profits are determined according to the Nash bargaining solution which establishes that the total increase in profit with respect to the non-cooperative equilibrium is equally divided between firms ${ }^{10}$. Thus, for each firm, we obtain

$$
\pi_{i}^{C}=\pi_{i}^{N}+\left(\Pi^{C}-\pi_{i}^{N}-\pi_{j}^{N}\right) / 2 ; i, j=H, L, i \neq j
$$

where $\Pi^{\mathrm{C}}$ indicates total cartel profits. Deviation profits, denoted by $\pi_{\mathrm{i}}^{\mathrm{D}}$, obtain by calculating the optimal deviation price for firm $i$ when firm $j$ remains loyal to the price agreement.

\subsection{Collusion without minimum quality standard}

We can first consider the case where firms collude in prices without the minimum quality standard. The global profits accruing to the cartel are $\Pi^{\mathrm{C}}=\left(8 \mathrm{~b}^{2}-16 b+9\right) / 32 \mathrm{t}$. Given the symmetry of the model, $\pi_{\mathrm{i}}^{\mathrm{C}}=\Pi^{\mathrm{C}} / 2$. On the basis of equations $(6 \mathrm{a}, \mathrm{b})$ and $(11 \mathrm{a}, \mathrm{b})$ it can be established that deviation leads to the following pairs of prices and profits for the low and the high quality firm, respectively:

$$
\begin{gathered}
p_{L}{ }^{D}=\left(48 b^{2}-112 b+101\right) / 128 t \\
p_{H}{ }^{D}=\left(48 b^{2}-16 b+41\right) / 128 t \\
\pi_{L}{ }^{D}=\left(16 b^{2}-32 b+51\right)^{2} / 12288 t \\
\pi_{H}{ }^{D}=\left(16 b^{2}-32 b+39\right)^{2} / 12288 t
\end{gathered}
$$

\footnotetext{
${ }^{10}$ For a seminal treatment of sharing rule of cartel profits in asymmetric settings, see Friedman (1977).
} 
We can now calculate the critical discount factors for the two firms without minimum quality standard:

$\alpha_{L}^{*}=\frac{\left(873-192 b+1120 b^{2}-1024 b^{3}+256 b^{4}\right)}{\left(297-3264 b+2656 b^{2}-1024 b^{3}+256 b^{4}\right)}$

In order to ensure that $\alpha_{\mathrm{L}}{ }^{*} \in[0,1]$ it is necessary that $\mathrm{b} \geq 2.61962$.

$\alpha_{H} *=\frac{\left(-207+576 b+736 b^{2}-1024 b^{3}+256 b^{4}\right)}{\left(-783-2496 b+2272 b^{2}-1024 b^{3}+256 b^{4}\right)}$

Similarly, it can be easily shown that $\alpha_{H} * \in[0,1]$ if $b \geq 1.90139$. In the interval $\left[2.61962, \infty\left[\right.\right.$, both $\alpha_{i}^{*}$ are increasing and concave in $b$.

\subsection{Collusion with minimum quality standard}

In the case of the minimum quality standard, we can calculate cartel and deviation profits for the two firms, following the same procedure shown above.

Collusive profits amount to, respectively,

$\pi_{L}^{C S}=\frac{\left(109206-42966 \sqrt{ } 6+84000 b-24000 b \sqrt{ } 6-42000 b^{2}+12000 b^{2} \sqrt{ } 6\right)}{(48000 t(7+2 \sqrt{ } 6))}$

$\pi_{H}^{C S}=\frac{\left(-172458+60138 \sqrt{ } 6+84000 b-24000 b \sqrt{ } 6-42000 b^{2}+12000 b^{2} \sqrt{ } 6\right)}{(48000 t(7+2 \sqrt{ } 6))}$

and deviation profits are

$$
\begin{aligned}
& \pi_{L}^{D S}=\left(190953+59292 \sqrt{ } 6-146400 b-129600 b \sqrt{ } 6+233200 b^{2}+64800 b^{2} \sqrt{ } 6-160000 b^{3}+\right. \\
& \left.+40000 b^{4}\right) /(384000 t \sqrt{ } 6(\sqrt{ } 6-1)) \\
& \pi_{H}^{D S}=\left(631777-242172 \sqrt{6}+520800 b+148800 b \sqrt{ } 6+420400 b^{2}-74400 b^{2} \sqrt{ } 6-\right. \\
& \left.160000 b^{3}+40000 b^{4}\right) /(384000 t \sqrt{6}(\sqrt{ } 6-1))
\end{aligned}
$$


Using the previous expressions, we can calculate the critical discount factors $\alpha_{i}^{\mathrm{S}}$ * (the expressions are presented in appendix C). In order to ensure that $\alpha_{L}{ }^{S_{*} \in[0,1]}$ it is necessary that $b \geq 1.25$. Analogously, $\alpha_{H}{ }^{3} *_{*} \in[0,1]$ if $b \geq 3.26553$, so that in the interval [3.26553, $\infty\left[\right.$ both $\alpha_{i}{ }^{S} *$ are increasing and concave in $b$. The effect of the introduction of the minimum quality standard on the critical discount factors and thus on the stability of the cartel is summarised in the following proposition.

Proposition 1: the introduction of the minimum quality standard makes collusive agreement more difficult to sustain as compared to the duopoly without standard.

Proof: simple numerical calculations show that $\alpha_{\mathrm{H}}{ }^{\mathrm{S}}{ }>\alpha_{\mathrm{H}} *$ for $\mathrm{b}>4.52953$. This implies that if $b$ is sufficiently high, the introduction of the minimum quality standard makes it more difficult for the high quality firm to stick to the cartel agreement. On the other hand, it is easily seen that $\alpha_{L}{ }^{S}>\alpha_{L} *$ for all $b>3.26553$, implying that for the low quality firm it is always more difficult to collude after the introduction of the standard. This entails that cartel stability is reduced by the introduction of the minimum quality standard.

This result is in line with the findings of Chang (1991) in a model of horizontal differentiation with quadratic transportation $\operatorname{costs}^{11}$. The difference in the critical discount factors for the two firms can be justified by the asymmetry in non-cooperative profits induced by the standard in favour of the low quality firm.

The behaviour of the critical discount factors in the two setting for each firm are represented in figures 1 and 2.

[Insert figure 1 about here]

[Insert figure 2 about here]

\section{Concluding remarks}

\footnotetext{
${ }^{11}$ As shown by Cremer and Thisse (1991), the Hotelling model with convex transportation costs is a special case of a vertical differentiation model with convex variable production costs.
} 
In this paper we have considered a model of duopoly à la Mussa-Rosen where firms produce only one variety and production involves variable costs convex in quality and an exogenous fixed cost. Building on the work of Crampes and Hollander (1995), we have considered the endogeneous setting of a minimum quality standard by a benevolent regulator aiming at maximising social welfare. In line with the previous literature, we have shown that the introduction of the standard (i) decreases the degree of differentiation in the market; (ii) reduces the market share of the high quality firm to the advantage of the low quality firm; (iii) increases social welfare in a way that the gains for the low quality firm and low income consumers outweigh the losses suffered by the high quality firm and high income consumers. We have also studied the effect of the introduction of the standard on the stability of collusion in the market stage of the game. In this respect, we have proved that the presence of the standard makes it more difficult for firms to collude in prices, if consumers' marginal willingness to pay for quality is sufficiently high. The reduction of cartel stability is due to the decrease of product differentiation which entails a higher incentive to deviate for both firms, although the asymmetry produced by the standard makes deviation more likely for the low quality firm. This final result is interesting in showing that the minimum quality standard, in addition to static welfare gains, yields also pro-competitive effects in the long-run. 


\section{References}

Besanko,D., S.Donnenfield, and L.J.White,(1987),'Monopoly and Quality Distortion: Effects and Remedies", Quarterly Journal of Economics, 102, 743-67.

Besanko,D., S.Donnenfield, and L.J.White,(1988),’The Multiproduct Firm, Quality Choice, and Regulation", Journal of Industrial Economics, 36, 411-29.

Boom,A.,(1995),"Asymmetric International Minimum Quality Standards and Vertical Differentiation", Journal of Industrial Economics, 43, 101-19.

Chang,M.-H.,(1991),'The Effects of Product Differentiation on Collusive Pricing”, Internation Journal of Industrial Organization, 9, 453-70.

Crampes,C. and A.Hollander,(1995),'Duopoly and Quality Standards", European Economic Review, 39, 71-82.

Cremer,H. and J.-F.Thisse,(1991),'Location Models of Horizontal Differentiation: A Special Case of Vertically Differentiation Models", Journal of Industrial Economics, 39, 383-90.

Cremer,H. and J.-F.Thisse,(1994),"Commodity Taxation in a Differentiated Oligopoly", International Economic Review, 35, 613-33.

Friedman,J. and J.-F.Thisse,(1993),'Partial Collusion Fosters Minimum Quality Differentiation, Rand Journal of Economics, 24, 631-45.

Haeckner,J.,(1994),”Collusive Pricing in Markets for Vertically Differentiated Products“, Internation Journal of Industrial Organization, 12, 155-77.

Itoh,M.,(1983),'Monopoly, Product Differentiation and Economic Welfare”, Journal of Economic Theory, 31, 88-104.

Motta,M. and J.-F-.Thisse,(1993),'Minimum Quality Standards as an Environmental Policy: Domestic and International Effects", Nota di Lavoro 20.93, Fondazione Eni Enrico Mattei, Milan.

Mussa,M. and S.Rosen,(1978),'Monopoly and Product Quality", Journal of Economic Theory, 18, 301-17.

Ronnen,U.,(1991),"Minimum Quality Standards, Fixed Costs, and Competition”, Rand Journal of Economics, 22, 490-504.

Ross,T.,(1992),"Cartel Stability and Product Differentiation”, Internation Journal of Industrial Organization, 10, 1-13.

Shaked,A. and J.Sutton,(1982),"Relaxing Price Competition through Product Differentiation", Review of Economic Studies, 49, 3-14.

Sheshinski,E.,(1976),'Price Quality and Quantity Regulation in Monopoly Situation", Economica, 43, 127-37. 
Spence,M.,(1975),'Monopoly, Quality, and Regulation”, Bell Journal of Economics, 6, 417-29. 


\section{Appendix A}

In this appendix we will show that the level of social welfare corresponding to the introduction of the minimum quality standard, denoted by $\mathrm{W}^{\mathrm{S}}$, cannot be increased if the social planner acts as a Stackelberg leader with respect to the high quality firm in setting the minimum quality standard. In that case, the social planner would maximise (9) with respect to $\mathrm{q}_{\mathrm{L}}$, taking into account the reaction function of the high quality firm, which corresponds to

$$
q_{H}=q_{L} / 3+(1+3 b) / 3 t
$$

The first order condition for a maximum would be defined as

$$
\delta W / \delta q_{L}=\left(130 b-73-40 b^{2}-260 t q_{L}+160 b t q_{L}+160 t^{2} q_{L}^{2}\right) / 162=0
$$

and the resulting minimum quality standard would be

$$
q_{L}^{S S}=(40 b-65+3 \sqrt{ } 145) / 80 t
$$

where superscript $S S$ indicates the minimum quality standard that maximises social welfare when the social planner mimics the behaviour of a Stackelberg leader.

Using (A.1), we can calculate the corresponding level of social welfare:

$$
W^{S S}=\frac{\left(47780 \sqrt{ } 145-451900-1972800 b+100800 b \sqrt{ } 145+1972800 b^{2}-100800 b^{2} \sqrt{ } 145\right)}{t(7891200-403200 \sqrt{ } 145)}
$$

It is then immediate to show that $\mathrm{W}^{\mathrm{S}}>\mathrm{W}^{\mathrm{SS}}$ and that the difference $\left(\mathrm{W}^{\mathrm{S}}-\mathrm{W}^{\mathrm{SS}}\right)$ is convex in $b$. 


\section{Appendix B}

In this appendix, we show the consumer surplus levels in presence of the minimum quality standard

$C S_{L}{ }^{S}=\frac{\left(-22944+6309 \sqrt{6}-15720 b+1920 b \sqrt{6}+9600 b^{2}-600 b^{2} \sqrt{ } 6\right)}{24000 t(7-2 \sqrt{ } 6)}$

$C S_{H}{ }^{S}=\frac{\left(-127098+49803 \sqrt{ } 6-26280 b+10080 b \sqrt{ } 6+32400 b^{2}-11400 b^{2} \sqrt{ } 6\right)}{24000 t(7-2 \sqrt{ } 6)}$

It is then immediate to verify that $\mathrm{CS}_{\mathrm{H}}{ }^{\mathrm{S}}-\mathrm{CS}_{\mathrm{H}}{ }^{\mathrm{N}}<0$ for $\left.\mathrm{b} \in\right] 2.219, \infty\left[\right.$, while $\mathrm{CS}_{\mathrm{L}}{ }^{\mathrm{S}}-\mathrm{CS}_{\mathrm{L}}{ }^{\mathrm{N}}>0$ for all admissible values of $b$. 


\section{Appendix C}

In this appendix the critical discount factors in presence of minimum quality standards are displayed:

$$
\begin{aligned}
\alpha_{\mathrm{L}} \mathrm{S}_{*}= & \left(542042982-217073952 \sqrt{ } 6+415569600 b-170985600 b \sqrt{ } 6-137704800 b^{2}+\right. \\
& \left.58612800 b^{2} \sqrt{ } 6-70080000 b^{3}+26880000 b^{3} \sqrt{ } 6+17520000 b^{4}-6720000 b^{4} \sqrt{ } 6\right) / \\
& \left(66499686-20330496 \sqrt{ } 6+66513600 b-32169600 b \sqrt{ } 6+36832300 b^{2}-\right. \\
& \left.10795200 b^{2} \sqrt{ } 6-70080000 b^{3}+26880000 b^{3} \sqrt{ } 6+17520000 b^{4}-6720000 b^{4} \sqrt{ } 6\right)
\end{aligned}
$$

$$
\begin{aligned}
\alpha_{\mathrm{H}} \mathrm{S}_{*}= & \left(-255433770+101016720 \sqrt{ } 6-29044800 b+13852800 b \sqrt{ } 6+84602400 b^{2}-\right. \\
& \left.33806400 b^{2} \sqrt{ } 6-70080000 b^{3}+26880000 b^{3} \sqrt{ } 6+17520000 b^{4}-6720000 b^{4} \sqrt{ } 6\right) / \\
& \left(-727613226+296469936 \sqrt{ } 6-378100800 b+152668800 b \sqrt{ } 6+259130400 b^{2}-\right. \\
& \left.103214400 b^{2} \sqrt{ } 6-70080000 b^{3}+26880000 b^{3} \sqrt{ } 6+17520000 b^{4}-6720000 b^{4} \sqrt{ } 6\right)
\end{aligned}
$$

